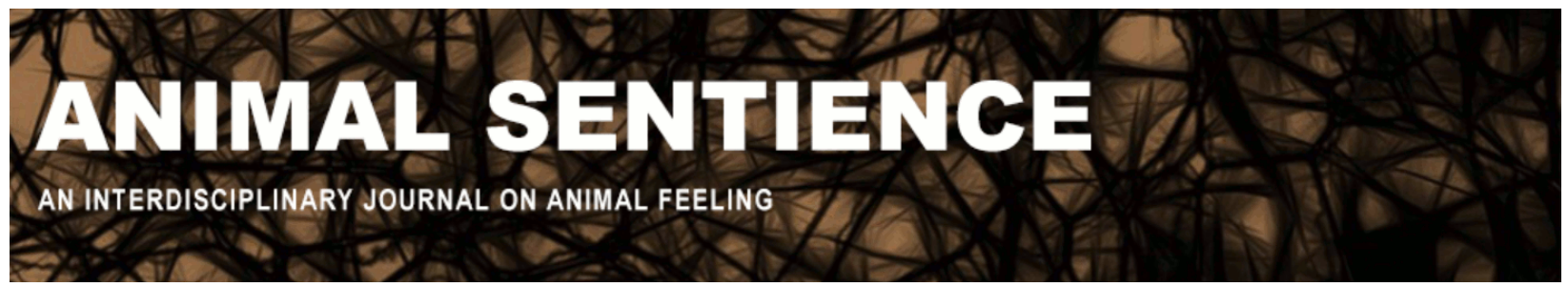

Porcher, Ila France (2019) On the sentience of sheep and other useful objects. Animal Sentience 25(8)

DOI: $10.51291 / 2377-7478.1441$

Date of submission: 2019-05-13

Date of acceptance: 2019-05-18 (c) 


\title{
On the sentience of sheep and other useful objects
}

Commentary on Marino \& Merskin on Sheep Complexity

\author{
Ila France Porcher \\ Independent Ethologist
}

\begin{abstract}
The nature of sheep has been in plain view ever since the animals were domesticated about 10,000 years ago. Why their intelligence, individuality, and emotional complexity has been ignored is a question that goes well beyond Marino \& Merskin's timely target article. Not only has cognitive bias in favour of religious ideas in biology been involved, but the territorial nature of our own species is implicated as well. The tendency of Homo sapiens to see others in terms of "us" and "them" has resulted in a history of racism, speciesism, and general domination of any others that could be fitted into the category of "lesser life forms." But whereas this tendency may be common to our species, science is supposed to be objective.
\end{abstract}

\begin{abstract}
Ila France Porcher is an ethologist who began writing books about the behaviour and intelligence of sharks when the population of several hundreds she had been studying, through underwater observation, was massacred for shark fin soup. She is the author of The Shark Sessions, The True Nature of Sharks, and Merlin: The Mind of a Sea Turtle. Website
\end{abstract}

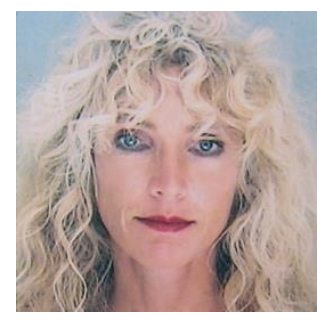

Marino \& Merskin (2019) (M\&M) raise the question of how many other biological assumptions have resulted from the religious idea that Homo sapiens stands superior to all, in a divine position at the apex of a hierarchy consisting of the other forms of life. It is unfortunate that these ideas were not among the scientific truths being discussed as agribusiness developed rather than appearing now as a sort of afterthought.

Many of the aspects of cognition and emotion described in M\&M's review have been in plain view for all to see since sheep were domesticated approximately 10,000 years ago. The animals' reported expressiveness through ear posture, for example, is common in mammals, including such familiar ones as the dog and the horse. The ability of sheep to recognize conspecifics and react to them as individuals, nervousness in threatening and unfamiliar situations, the attachment between the ewe and lamb, and the post traumatic stress syndrome effect have been evident to anyone who cared to look, as well the general mammalian characteristics of the sheep.

M\&M begin appropriately by pointing out how folklorish ideas have been entertained by the general public when dealing with sheep, and also how they have infested a biology that used them to serve human needs, apparently without doing the pure research necessary to document their true qualities as independent forms of life.

Not only does this remind us that scientific thinking has not been adopted by society in general - it shows us that even in scientific circles, sheep have been so despised as a result of 
their low place in "God's hierarchy," that no one felt they were worth investigating as animals and individuals. But the scientific quest has traditionally had the responsibility to seek the truth independently of the folklore of the times. Scientific objectivity and the scientific method are supposed to be our trusted defence against the falsity of beliefs that are taken from the doxa and unsubstantiated by factual evidence. Thus M\&M's paper actually reveals a blind spot in science. Kahan and his team (2013), researchers at Yale, found that belief is more important in the human mind than evidence, and that this is just as true of scientists as of the general public. Such cognitive bias, in which all new information is fitted into a preconceived belief, could be applicable in this case.

Thus, this paper says as much about biology's approach as it does about sheep, for a similar review could likely be written about any of the animals sneered at by society and biologists, and used, not only to fulfill such human needs as food and clothing, but to be experimented upon at whim, with concern for neither their suffering nor their actual qualities. The demeaning way that sheep are treated, to the degree that they, as well as other farmed animals, are exempt from protection by the Animal Welfare Act, is a sad commentary on the current state of biology, which, in this context at least, appears to have had no ethical concern other than to serve industry. With masses of evidence of sentience in animals from the apes to fish (Bshary et al. 2002), it would defy evolutionary continuity to suggest that sheep and the other animals caught up in agribusiness are not sentient. Another case in which scientific findings are being fought by scientists defending industry is fisheries science (Sneddon et al. 2018; Shiffman \& Hueter 2017; Porcher et al. 2019; Porcher 2017).

M\&M point out that the scala naturae are a subconscious measure used by humans to determine the status of others:

"The model [scala naturae] offers an explanation for the human propensity to determine the value of others on the basis of similarity to (or difference from) ourselves."

However, this model had not been written when sheep were first domesticated; it is unlikely that they were treated with respect until the scala naturae was adopted. The tendency to dominate others, especially those weaker or more passive, is a strong instinct in Homo sapiens, which, it is self-evident, is a highly territorial and violent species. The way stronger individuals, cultures, and nations have always tried to dominate the weaker ones is seen throughout history, and in contemporary society from the family unit to the international level (Lorenz 1963).

M\&M also find that, "Women were more concerned with animal welfare than men." This is a further indication that human instincts are at play since women's mothering instincts might make it more difficult for them to face and accept deliberate cruelty, compared to men who have tended to turn to physical violence as part of their efforts to dominate others.

Biology's investment in agribusiness, the pharmaceutical industry, the pesticide industry, the biological warfare industry, the fishing industry, and the leather and fur industries, to name just a few, shows the same pattern of treating nature and animals as being there to serve the human project only. Over the centuries, this approach has resulted in a failure to understand both nature and life. 
Lorenz wrote in 1963:

"Philosophical anthropology of a type neglecting biological fact has done its worst by imbuing humanity with that sort of pride which not only comes before, but causes a fall."

The situation has scarcely improved. Congratulations to M\&M for spotlighting this phenomenon.

\section{References}

Bshary, R., Wickler, W., \& Fricke, H. (2002) Fish cognition: A primate's eye view. Animal Cognition, 5, 1-13.

Kahan, D. M., Peters, E., Dawson, E., \& Slovic, P. (2013) Motivated numeracy and enlightened self-government. Behavioural Public Policy, 1, 54-86; Yale Law School, Public Law Working Paper No. 307.

Lorenz, K. Z. (1963) Das Sogenannte Böse: Zur Naturgeschichte der Aggression, by V. Dr BorothaSchoeler, Vienna, Austria.

Marino, L., \& Merskin, D. (2019) Intelligence, complexity, and individuality in sheep. Animal Sentience 25(1)

Porcher, I. F. (2017) The true nature of sharks. Independently published, Hope, B.C., Canada.

Porcher, I. F., Darvell, B. W., \& Cuny, G. (2019) Response to “A United States shark fin ban would undermine sustainable shark fisheries" D.S. Shiffman \& R.E. Hueter, Marine Policy 85 (2017) 138-140. Marine Policy, 104, 85-89.

Shiffman, D. S., \& Hueter, R. E. (2017) A United States shark fin ban would undermine sustainable shark fisheries. Marine Policy, 85, 138-140.

Sneddon, L. U., Lopez-Luna, J., Wolfenden, D. C. C., Leach, M. C., Valentim, A. M., Steenbergen, P. J., Bardine, N., Currie, A. D., Broom, D. M., \& Brown, C. (2018) Fish sentience denial: Muddying the waters. Animal Sentience 21(1) 